\title{
The World Health Organization Global Health Emergency Workforce: What Role Will the United States Play?
}

\author{
Frederick M. Burkle, Jr., MD, MPH, DTM
}

\section{ABSTRACT}

During the May 2016 World Health Assembly of 194 member states, the World Health Organization (WHO) announced the process of developing and launching emergency medical teams as a critical component of the global health workforce concept. Over 64 countries have either launched or are in the development stages of vetting accredited teams, both international and national, to provide surge support to national health systems through WHO Regional Organizations and the delivery of emergency clinical care to sudden-onset disasters and outbreak-affected populations. To date, the United States has not yet committed to adopting the emergency medical team concept in funding and registering an international field hospital level team. This article discusses future options available for health-related nongovernmental organizations and the required educational and training requirements for health care provider accreditation. (Disaster Med Public Health Preparedness. 2016;10:531-535)

Key Words: emergency medical teams, Global Health Emergency Workforce, World Health Organization (WHO), Pan American Health Organization (PAHO), disaster medicine, humanitarian assistance

A major advancement, post-Ebola, designed to ensure a credible global health emergency workforce for future public health emergencies of international concern (PHEICs) has been the process of the World Health Organization (WHO) of establishing a formal quality-assured list of international emergency medical teams (EMTs), certified with pre-event vetting and adherence to minimum standards of care. The former emphasis on foreign medical teams alone is now replaced by EMTs that are both international (I-EMTs) and national (N-EMTs). EMTs play a critical role by providing surge support to national health systems through WHO Regional Organizations (Figure 1) and the delivery of clinical care to disaster- and outbreak-affected populations. With the classification and quality assurance of EMTs, the WHO can guarantee disaster-affected governments and their populations with predictable and timely responses by well-trained medical personnel and self-sufficient teams. EMT's operational signatures are their robust sustainable capacities as large field hospitals with surgical or infectious disease multidisciplinary treatment teams capable of managing trauma and public health emergencies.

\section{EMERGENCY MEDICAL TEAMS}

Currently, 64 EMTs are complete or in development representing both I-EMTs and N-EMTs from 25 countries, international nongovernmental organizations (NGOs), and both the International Committee of the Red Cross (ICRC) and the Federation of the Red Cross and Red Crescent Societies (IFRC). ${ }^{1}$ The WHO EMT quality-assured list and classification system is for NGOs and governmental teams, each of which is then expected to have registered and maintained a pool of accredited volunteers within it. This force multiplication is profound, with the anticipated final figure of over 200 EMTs globally representing a health emergency workforce of over 100,000 people (I Norton, personal communication, May 26, 2016).

EMTs must comply with the classification and minimum standards for EMTs in sudden-onset disasters verified in 2013 by the WHO Foreign Medical Team Working Group and the Global Health Cluster. WHO's new classification system ensures a global roster of EMTs with credentialed health care providers and multidisciplinary managers and staff trained and self-sufficient so as not to burden the national systems. When a crisis occurs that demands the global health workforce, the WHO will coordinate with EMTs and help affected governments understand the bilateral offers of support and direct them to where they are needed the most. Those teams that have been WHO-quality-assured are far more likely to be given rapid access along with their supplies and will be preferentially selected by affected countries. While EMTs are registered according to their capability and capacity, global registration does not guarantee an invitation to be deployed, as this depends on overall needs, context, logistical support, and resources. ${ }^{2}$ 


\section{FIGURE 1}

\section{World Health Organization Regional Organizations.}

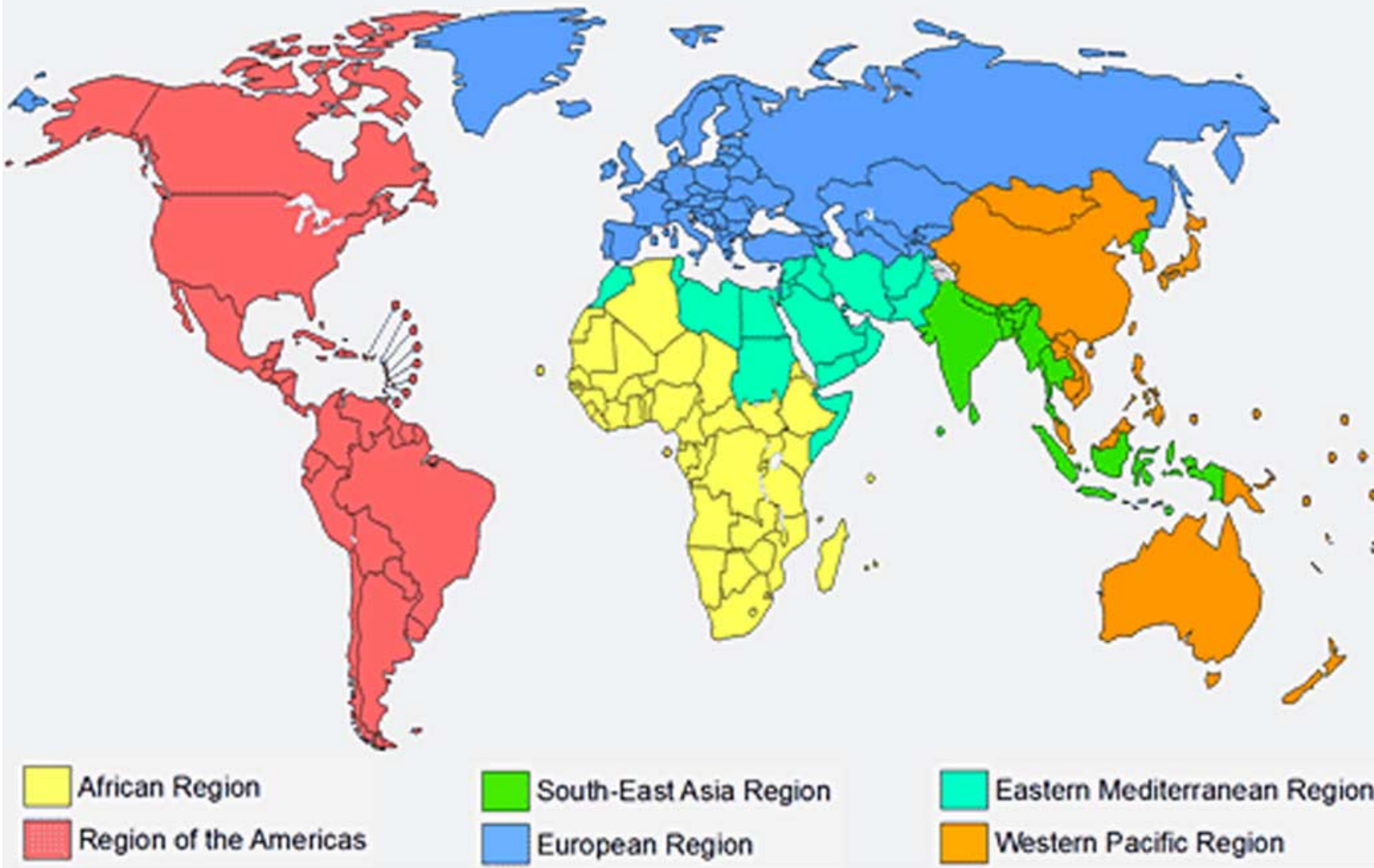

EMTs are classified as Type 1 (Outpatient Emergency Care) for initial emergency care of injuries and other significant health care needs, Type 2 (Inpatient Surgical Emergency Care) for general and obstetric surgery for trauma and other major conditions, and Type 3 (Inpatient Referral care) for complex inpatient referral surgical care including intensive care capacity. Individual countries will still determine whether EMT support is needed. ${ }^{2}$

Each EMT represents not just the 50 or more professionals they can send to the field, but deep rosters of 500 to 1000 staff who have trained to deploy in second or third waves of rotation. Many of the governmental teams come from their public health services and government hospitals. They work daily on the wards but have a special interest in local, national, and international response and spend some of their weekends training and practicing. For example, Japan has a volunteer pool of trained disaster medical assistance teams numbering 10,000 people, of which the top 1000 are selected to join the Japanese disaster relief (JDR) team run by the Japan International Cooperation Agency. They have responded to disasters for over 20 years, but were unable to send teams to the Ebola epidemic, so they decided to develop another form of a JDR clinical team for direct infectious disease patient care (I Norton, personal communication, May 26, 2016). This represents a large commitment and shows a willingness to step up and deliver when knowledge gained through experience shows an operational gap.

Concerns over potential for noncompliance of the humanitarian principles of humanity, neutrality, impartiality, and independence among deployed military assets have, so far, been minimized. Teams must declare their adherence to these principles to the $\mathrm{WHO}$ during the peer review process. Whereas China has used military forces to undertake international humanitarian assistance and disaster relief with 12 missions since 2002, they recognized that such deployments can have "significant downside risks." Both the China and Russia EMTs are completely staffed by civilians, do not use military aircraft for transport, and are jurisdictionally based under their respective ministries of health or civil protection and emergency response. Although military logistical capacity was irreplaceable in West Africa's Ebola epidemic, in the future it cannot be guaranteed. In the 
West African deployment, no US military-deployed Public Health Service personnel or Centers for Disease Control and Prevention (CDC) staff treated any Ebola victims.

In this April's Ecuadorian earthquake, their Ministry of Health along with concurrence of the Pan American Health Organization (PAHO)/WHO only invited regional EMTs from Spanish-speaking countries including Colombia and Mexico. PAHO/WHO had been in the country just 10 days before the earthquake struck, training the Ministry of Health to create an EMT "coordination cell" (EMT-CC) to better manage their own N-EMTs and understanding how to call on and coordinate the I-EMTs available on the WHO classified list. They sent over 20 of their own Type 1 teams to the scene in hours and quickly identified that the only gap was for 2 Type 2 field hospitals and a health logistics and hospital repair team. Over 10 other small teams from the region and beyond arrived, some with the knowledge and agreement of the EMT-CC but others who were only found later (I Norton, personal communication, May 26, 2016). This form of middle-income country self-managed national response with specific, targeted, and timely international assistance by the WHO and EMTs (both government and $\mathrm{NGO)}$ is likely to become more and more common, particularly in the disaster-prone regions of Latin America, South America, South East Asia, and the Pacific. Much of developing Africa is in a similar position but is plagued by conflict and other geopolitical challenges that are also indigenous in the Middle East. Europe and North America will also expect a similar approach of a national government taking charge, describing its needs, and expecting rapid and quality-assured response from its neighbors with WHO assistance.

Additionally, many governmental EMTs can move in 3 to 6 hours and call on hundreds of governmental employees with the insurances, training, and self-sufficiency all prearranged. This relatively new phenomenon has shown a speedup in heavy lift, with well-trained EMTs arriving in the first hours or days. Peak time to field hospital bed deployment in Haiti was day 17, but some 100 teams arrived in the first 5 days to Nepal, with governmental and military teams the largest and fastest (I Norton, personal communication, May $26,2016)$. Trauma care in disasters is all about time and not just arrival; health care delivery must start within 72 hours to be most effective. ${ }^{4}$

This is the critical gap that regional countries will require in the hours after a disaster. These hospitals must be multi-use and capable of being reconfigured for infectious disease response if required. This should be a two-tier system with those trained for local and national response having extra levels of training and preparation to be ready for international deployment (similar to existing Japanese, Australian, and US urban search and rescue teams), especially in resource-poor settings and with the increasing potential for nuclear catastrophes. $^{5}$
Unfortunately, the Global Health Cluster approach to compliance and management of disparate NGOs and their capability to analyze crucial health outcome data has fallen short and has been openly criticized for its lack of "formal decisionmaking mechanisms or mandates," leaving many disasterprone countries to disapprove of the system. ${ }^{6}$ EMTs and the crisis events they would be mobilized for are not at all similar to the daily bread-and-butter health NGO activities they are known for (primarily Type 1) and which will always be available in the prolonged recovery and rehabilitation phases of any crisis. PHEICs and sudden-onset trauma and surgical events are unique, complex, and demanding and are often plagued by security issues beyond the capacity of most NGOs.

\section{ACCREDITED EDUCATION AND TRAINING}

Education and training requirements for EMTs include competencies for work in a resource-poor or constrained environment, such as that procedures are performed only by those licensed and accredited to do so and that they adhere to standardized data collection and reporting, meet professional and ethical standards, are self-sustainable, are staffed by personnel with experience in humanitarian settings, and have a process in place to supervise those less experienced. Justin-time "adaptation" training for the context, culture, and country specifics of humanitarian and global health response outside of their country also includes team and individual preparation for security.

Over the past 3 decades, over 14 academic training centers in North America under the Professional Association for Academic Training Centers in Humanitarian Health (PAATCHH) have provided the bulk of the competencybased education and training opportunities for prospective humanitarian aid workers as well as ensuring standards of care, transparency, and accountability necessary to keep providers current in a very rapidly changing global health environment. ${ }^{7-9}$ These courses continue but with the current lack of humanitarian opportunities can no longer guarantee an EMT placement for their graduates. A similar educational consortium, modeled after the PAATCHH, was recently formed by academic training centers in the European Union including Turkey and Israel to support their respective WHO Regional Organizations.

Unfortunately, predeployment accredited training has not been a requirement for the development of health-related NGOs in the past. Some teams, including those from the United States, responding to the large-scale earthquakes in Nepal and the Philippines arrived without the capacity to be self-sufficient (I Norton, personal communication, May 26, 2016). Not infrequently, health providers had to learn quickly that their specialty training alone was not enough and that they lacked the operational skill sets and collaborative leadership capacity required for the demands of resource-poor decision-making and the complexities of public health 
emergencies such as epidemics. In a global health emergency workforce, these actions would not be tolerated or expected to occur with appropriate predeployment accredited EMT training. Teams that arrive without explicit request of the country and the WHO Regional Organization will be turned away at the airport. Under the EMT concept, all countries share in the responsibility to "ensure that cross-disciplinary, competency-based knowledge and field-related tasks are practiced globally with the highest standards of care."10

\section{OPTIONS FOR EMT DEPLOYMENTS BY THE UNITED STATES}

In past decades, the US global response to health care emergencies has come primarily from health-related NGOs who must build up their resources and volunteer health care providers before deployment while remaining dependent on instant visibility and publicity for sustainability through the generation of donations. They are quite unlike Médecins Sans Frontières (MSF), which has enough in financial reserves to cover 10 months or more of unanticipated crisis activities that allow for a "quick deployment to a sudden major emergency." 11 As such, MSF was first on the scene in West Africa to alert the world of Ebola's spread and unselfishly assisted arriving NGOs from many countries with just-in-time training. MSF also assisted them and the WHO in the proper placement of where they could do the most good.

As of this writing, any formal support or planning from the US government to field either I-EMTs or N-EMTs is lacking. Some NGOs see their futures threatened by the EMT movement while others have entered their names in the WHO registry as potential Type 1 deployment teams only, not for the more robust Type 2 or Type 3 self-sufficient rapid-deployment EMTs (see the figure from the Policy, Practice and Evaluation Unit, Emergency Risk Management and Humanitarian Response Office, WHO, Geneva, in the online data supplement).

International Medical Corps has just acquired the 4-year-old Office of Foreign Disaster Assistance field hospital but do not have any immediate plans to register as an EMT nor do they have adequate funding or a permanent roster of accredited health care providers. The health-related NGOs should reconsider the option, open to the WHO, for them to collaborate, consolidate, and coordinate their assets and requests for funding to form 1 or 2 robust I-EMTs, which are probably the same NGOs they found themselves working closely with during the Ebola epidemic.

If the US government deems in the future to field I-EMTs, they should seriously consider how to use the US's extensive response capacities for health, such as the US Public Health Service, the experienced pool of trained civilian health care providers, US military logistical capacity, and its National Disaster Medical System to create at least 1 or 2 rapid-response, heavy-lift humanitarian field hospitals of Type 2 or 3 . While there has been some senior-level visibility and discussions within the US government on possibilities of reconfiguring existing International Medical Surgical Response Teams and fielding CDC public health teams during PHEICs, developing a volunteer registry in the United States to support and properly train credible operational teams quickly to ensure accredited team members will take more time and expense. Additionally, models that exist within other countries that integrate both search and rescue and health-related assets under one unified command must be considered.

The PAATCHH educational and training consortium has the capacity to ensure future accredited training centers, their faculty, and graduates in a North American and PAHOapproved registry for any regional EMTs. Additionally, educational consortium members can assist in the development of additional academic training centers and faculty to support $\mathrm{PAHO} / \mathrm{WHO}$ 's regional scope of responsibility and to continue that training in other countries where US trainers are already involved, such as China, South America, and the Asia-Pacific. The eventual aim of the WHO EMT initiative is for national EMTs in every country with strong regional mechanisms to be inextricably linked to the 2007 International Health Regulations capacity building and Global Health Security Agenda, both of which rely on strong trained national staff, with help from neighbors when required.

The pace and magnitude of tragic events, both natural and geopolitical, have accelerated. The global community, especially the millennial generation, see this long-overdue EMT movement less as a national effort per se and more as a shared obligation of global citizenry. Countries are not competing. However, many humanitarians are rightfully confused by the current US silence, especially in an area where we were once most admired and singled out for our altruism and innovations. As such, whatever outcome decisions result from internal US government discussions, EMT assets must reflect capabilities that permit response under circumstances in which both natural disaster and conflict are a catalyst and pose an ongoing risk to those deployed. Not all EMTs will qualify for both.

Unfortunately, as of the present writing, little will be accomplished in the US during an election year and the likelihood of an immediate request for funded, substantive, well-trained and educated US international EMTs in the coming months is very unlikely. Congress has struggled to consider the Zika virus a health emergency that warrants adequate funding; the CDC Director was incensed declaring that "This is no way to fight an epidemic." ${ }^{12}$ Clearly, to some the EMT issue will not be seen as a priority let alone a blip on the radar screen.

However, in the rest of the world, interest and intent on this topic are progressing at a rapid pace. After the surprise announcement at the World Health Assembly, this issue is sure to become a point of contention at upcoming disaster 
and crisis management conferences where organizers are rushing to include it on their agendas. While some discussions and debates have occurred within US government agencies, future discussions must include as partners those who for decades have educated, trained, and evaluated the humanitarian workforce. It is time to maturely sit with the broader and highly experienced humanitarian community and the academic education, training, and research centers staffed by seasoned aid professionals to explore where these assets might lead to sensible options for a collaborative and cooperative effort for the United States, both within PAHO's regional reach and globally.

\section{About the Author}

Harvard Humanitarian Initiative, Harvard University, Cambridge, Massachusetts, and Woodrow Wilson International Center for Scholars, Washington, DC.

Correspondence and reprint requests to Frederick M. Burkle, Jr., MD, MPH, Harvard Humanitarian Initiative, 14 Story Street, \#2, Cambridge, MA 02138 (e-mail: fburkle@hsph.harvard.edu).

\section{Supplementary material}

To view supplementary material for this article, please visit http://dx.doi.org/10.1017/dmp.2016.114

\section{REFERENCES}

1. World Health Organization. China and Russia teams join WHO's Emergency Medical Team Initiative. WHO website. http://www.who.int/ mediacentre/news/releases/2016/emergency-medical-teams/en/. Published May 26, 2016. Accessed June 10, 2016.

2. Humanitarian Health Action. Emergency Medical Teams and World Health Organization. WHO website. http://www.who.int/hac/techguidance/ preparedness/emergency_medical_teams/en/. Accessed May 22, 2016.
3. Yates A. China's risk equation: using military forces in international humanitarian assistance and disaster relief activities. Institute for Security and Development Policy. Stockholm, Sweden. ASIA Paper. http://isdp.eu/publication/chinas-risk-equation-using-military-forcesinternational-humanitarian-assistance-disaster-relief-activities/. Published January 1, 2013. Accessed June 10, 2016.

4. Pan American Health Organization. WHO-PAHO Guidelines for the Use of Foreign Field Hospitals in the Aftermath of Sudden-Impact Disasters. International Meeting: Hospitals in Disasters-Handle with Care. San Salvador, El Salvador, 8-10 July 2003. http://www.who.int/ hac/techguidance/pht/FieldHospitalsFolleto.pdf. Accessed May 21, 2016.

5. Burkle FM, Dallas CE. Developing a nuclear global health workforce amid the increasing threat of a nuclear crisis. Disaster Med Public Health Prep. 2016;10(1):129-144.

6. Schuller M. Killing with Kindness: Haiti, International Aid, and NGOs. New Brunswick, NJ: Rutgers University Press; 2012.

7. Burkle FM, Walls AE, Heck JP, et al. Academic affiliated training centers in humanitarian health, Part I: program characteristics and professionalization preferences of centers in North America. Prehosp Disaster Med. 2013;28(2):155-162.

8. Cranmer H, Chan JL, Kayden S, et al. Development of an evaluation framework suitable for assessing humanitarian workforce competencies during crisis simulation exercises. Prehosp Disaster Med. 2014;29(1):69-74.

9. Johnson K, Idzerda L, Baras R, et al. Competency-based standardized training for humanitarian providers: making humanitarian assistance a professional discipline. Disaster Med Public Health Prep. 2013;7(4): 369-372.

10. Global Health Cluster. Coordination and Registration of Providers of Foreign Medical Teams in the Humanitarian Response to Sudden-Onset Disasters: A Health Cluster Concept Paper. WHO. Interagency Standing Committee GHC Policy and Strategy Team Position Paper. http://www. who.int/hac/global_health_cluster/about/policy_strategy/fmt_concept_ paper_27_May.pdf. Published 2010. Accessed May 31, 2012.

11. Medecins Sans Frontiers. 2014 International Financial Report. http://cdn.msf.org/sites/msf.org/files/msf_financial_report2014_info.pdf. Accessed May 26, 2016.

12. Herszenhorn DM. Senate votes to advance emergency funding to fight Zika Virus. New York Times. http://www.nytimes.com/2016/05/18/us/ zika-senate-vote-emergency-funding.html?_r=0. Published May 17, 2016. Accessed June 1, 2016. 